\title{
Blue Revolution in Gujarat (India)
}

\author{
Manoj M Sharma* \\ Mayank Aquaculture Pvt Ltd, India
}

*Corresponding author: Manoj M Sharma, Director, Mayank Aquaculture Pvt. Ltd, 204-205 Suryadarshan Complex, Jahingirpura, Rander Road, Surat, Gujarat State, India

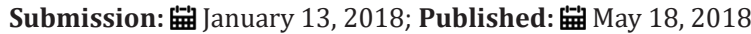

\section{Introduction}

During recent years, shrimp aquaculture industry in Gujarat is gaining immense in terms of area, production as well as socioeconomics. Presently, this massive brackish water aquaculture industry is one of the important agro-industry in the state. Its rapid development has attracted considerable attention in recent years. In spite of fact that, Gujarat is having second largest brackish water potential area (376000 hectares) in country next to West Bengal (405-500 hectares) in 14 coastal districts that contains $1600 \mathrm{Km}$ of coast line. From these potential areas, only 4249.95 hectares have been allotted to farmers for culture and presently, $0.83 \%$ (3116 hectares) from these potential areas has been developed and utilized for shrimp farming.

Shrimp farming in Gujarat started with 4.5 hectares in 1991-92 with an average production of $377.80 \mathrm{Kg} / \mathrm{ha}$ and then extended to 2500 hectares with an average production of $1840 \mathrm{Kg} / \mathrm{ha}$ in year 2008-09. The main culture species was Penaeus monodon (Black Tiger). Surat is the economic capital of Gujarat state, which is famous for its diamond and textile industry in India. This is one of the famous coastal districts that identified approximately to 24,300 hectares of potential brackish water area. Shrimp farming in Surat started with 6ponds at village Dandi (Olpad) under the technical guidance of Dr. Manoj M. Sharma in year 1995-96. Initially the production was not successful by virtue of viral outbreak of W.S.S.V. in the country followed by the Supreme Court stay-order. However, the culture practice was reattempted in year 2000 and production was very successful. The total production was 8 tons from these 6 ponds. This enlightened result has attracted the local community and entrepreneurs to push this industry towards massive scale.

The new era of shrimp farming begin in 2010 with introduction of Pacific white shrimp Litopenaeus vannamei, the SPF and High health status was the lead attraction with high production capacity. Shrimp farming industry hugely benefited after the introduction of vannamei species and within few years the national production went up manifold increase, from 80000ton to 380000ton in 2016. Presently Gujarat is producing 45000tons of high quality shrimp from 6500hectare @ 7000kg/hectare. To make this industry more sustainable, the major shrimp farmers and entrepreneurs joined hand-to-hand under one roof named Surat Aquaculture Farmers
Association (SAFA). SAFA took birth in year 2005 with primary motive to carry out sustainable shrimp farming with eco-friendly approach. Presently, SAFA is having 200 member farmers under this united roof.

\section{Objective of SAFA}

A. To carry out sustainable shrimp farming activity in Surat area.

B. To provide all members best available seed, feed and other necessary input information.

C. To provide all necessary guidelines to successful shrimp farming.

D. To make group marketing for better farm gate shrimp price.

\section{Achievement of SAFA}

A. Single largest group of farmers doing joint shrimp farming in India.

B. Developed more than 2500 hectares of culture area for shrimp farming in last 10 years.

C. Producing more than 18000 tons of high quality shrimp per annum with international repute.

D. Providing employment to 10000 peoples and indirect benefit to 22 coastal villages.

E. Generating foreign exchange for the state and country.

\section{Future Plan of SAFA}
A. To create a cooperative blue revolution movement in Gujarat.
B. To establish all state of the art export oriented facilities.
C. To develop own brand and establish domestic shrimp market in India.
D. To develop more than 50000 hectares of ponds in Surat.
E. To create self-employment for 100000 families. 


\section{Successful Salient Shrimp Farming Activity in Surat}

Naturally shrimp habituates in sea or in large brackish water bodies, from where it takes all necessary nutrients for its growth and metabolism. Its captive culture inside pond with relatively high density needs scientific care to make its culture sustainable and economical without causing adverse environmental impact. However, the following briefs are some important management aspects, which were practiced in Surat area for successful shrimp farming.

\section{Site Selection}

Site selection is very important factor of success for any industry. Surat is blessed with nearly 24300 hectares of brackish water area; suitable for aquaculture and from these presently, 1500 hectares of shrimp farms are developed with proper micro level survey by MPEDA and Govt. of Gujarat. In these entire sites were selected as per topography, climatic conditions, water quality, susceptibility or vulnerability to pollution, accessibilities and logistics. A developed and planned area from Surat is given in (Figure 1).

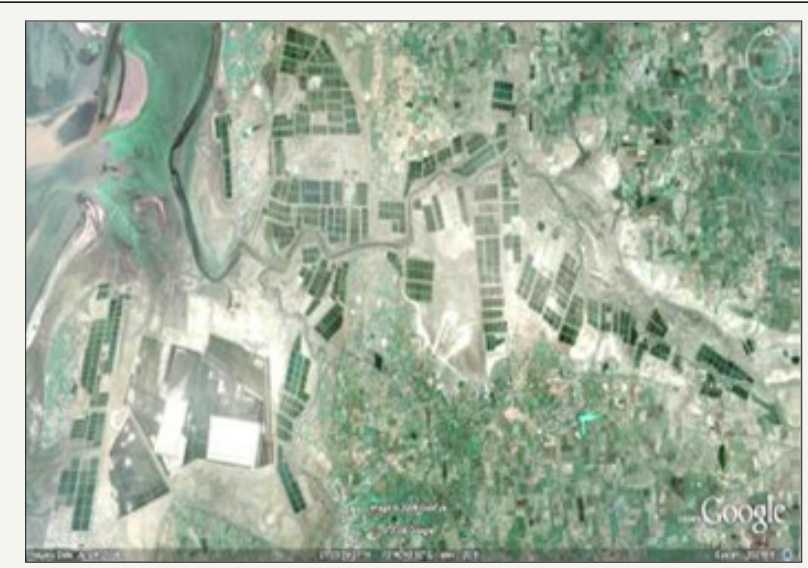

Figure 1: A developed site (Olpad) from Surat.

\section{Design and Construction of Farms}

Design and construction of farm plays a vital role in success of shrimp farming and its management. All the shrimp farms in Surat were properly designed and constructed as per the tips given below:

A. Proper ratio of settlement and reservoir to culture ponds were maintained as per 5:20:75. This is one of the most important factors, which usually gives more successful crop of shrimp in Surat area. The above ratio is strictly followed in all farms, while making design and construction. The key of design is to reduce the turbidity of sourced water through proper settlement and reservoir ponds, which is very effective in managing better water quality in shrimp ponds.

B. Culture ponds used to construct with size varied from 0.8 - 1.0ha.

C. Good water depth used to maintain with average 1.8 meters. This is used to increase the carrying capacity of water, for better environment, of shrimp. This factor resulted in increasing better unit production compared to other shallow pond.

D. Proper pond bed slope and drainage facilities were maintained i.e. 10-12 inches per 100 meters gradient, which is very good for pond bottom flushing and effective harvest.

E. Good pumping capacity used to follow in all farms for effective water management

\section{Some selected photographs showing key points of constructions in Surat}

(Figure 2-5).

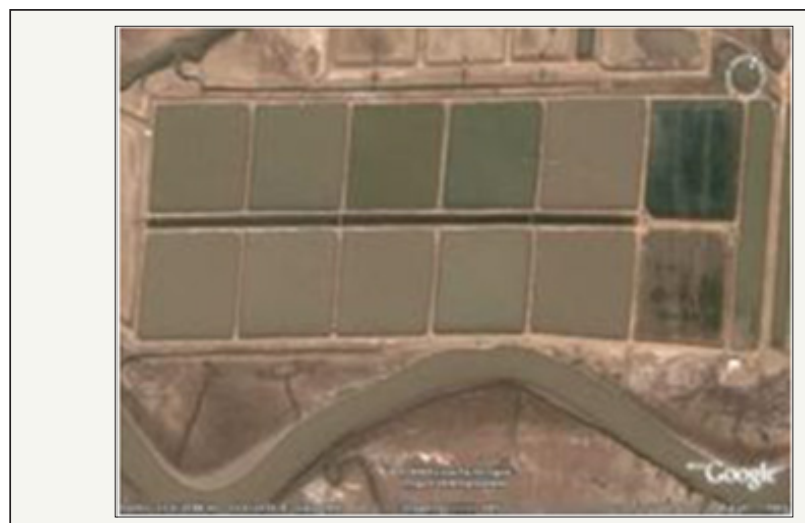

Figure 2: A well constructed farm in Surat area showing settlement, reservoir and culture ponds with 5:20:75 ratio.

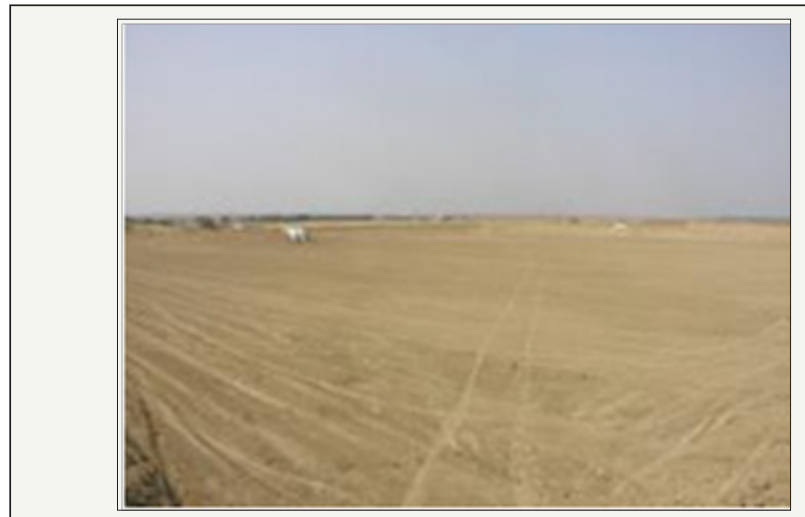

Figure 3: A well constructed pond in Surat area.

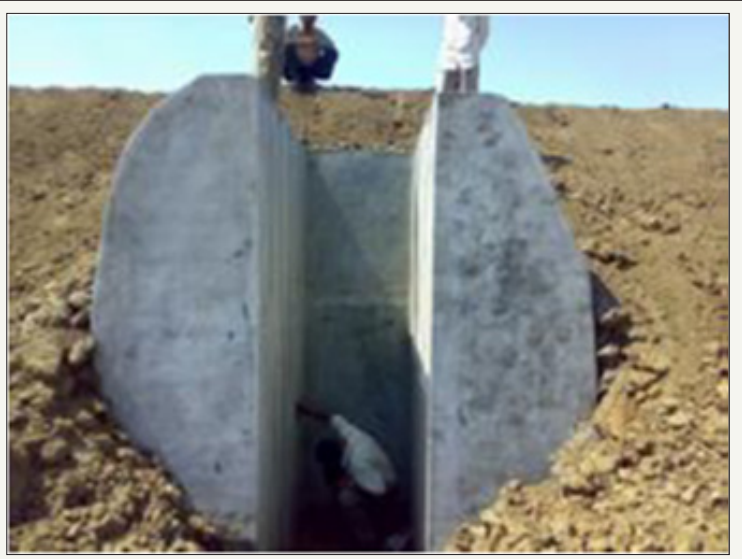

Figure 4: A constructed pond indicating Depth at out let. 


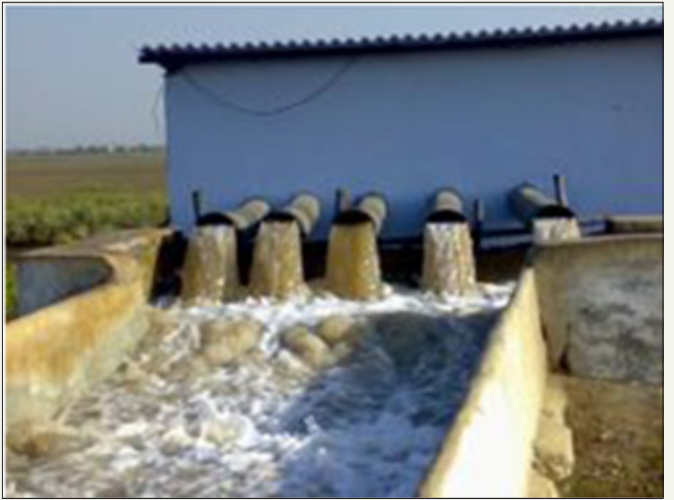

Figure 5: A farm showing pumping efficiency.

\section{Pond preparation practices}

Well begin is half done, for the success of shrimp farming initial pond preparation is very important step before stocking of shrimp in the pond. Good pond preparation includes drying, ploughing, compacting, water culturing with good pre \& pro-biotic. This results in good natural food production, which serves as primary food for the growing shrimp with good survival. In Surat area pond preparation is practiced in several steps prior to stock post larvae as brief given below.

A. Proper drying of old culture ponds are done, until deep crack are formed as the figure given below. (Figure 6).

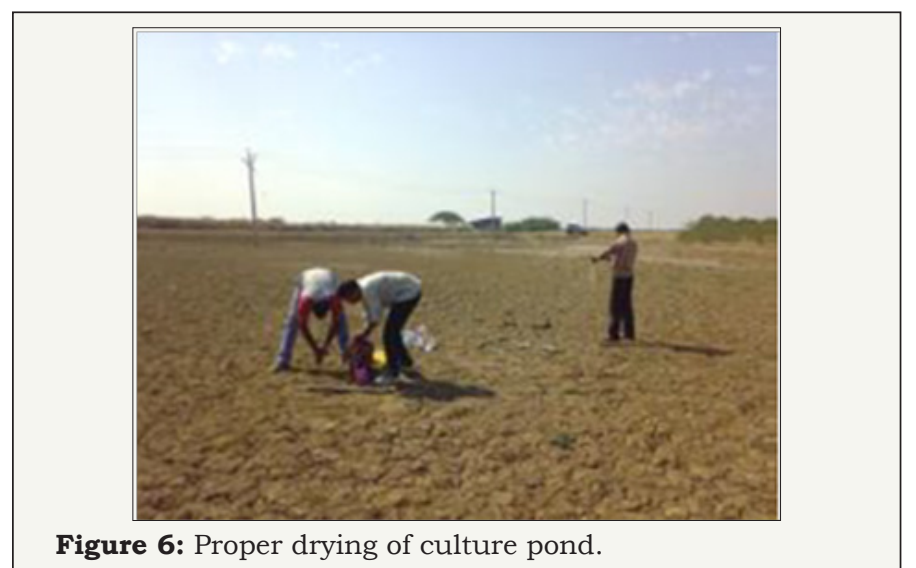

B. Proper ploughing for effective oxidation of pond bottom soil used to carry out, followed by compaction as showed in figures (Figure 7-8).

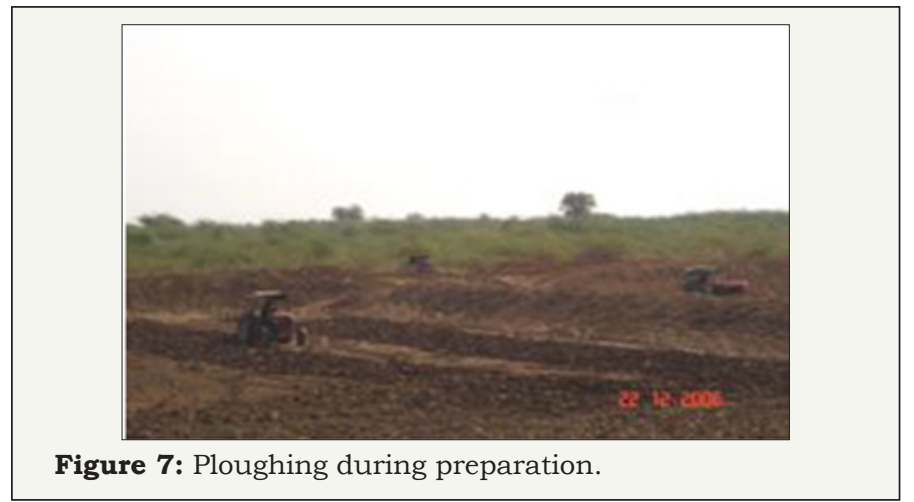

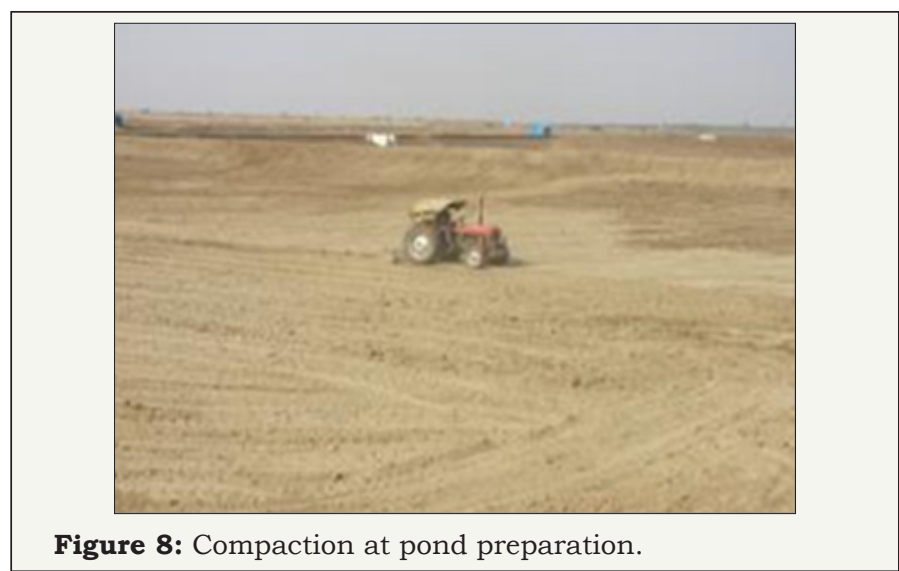

C. Proper disinfection of the bottom soil is strictly followed.

D. In all farms, water used to pass through multiple filter chambers consisting of mesh sizes like 20, 40,60 and 80 prior filling the culture ponds as figure below. This is another important practice under biosecurity in Surat area that makes this industry more successful at the juncture of viral out break. This multiple filtration system prevents the entry of active carriers of shrimp virus, thus reduce the chance of horizontal transmission (Figure 9).

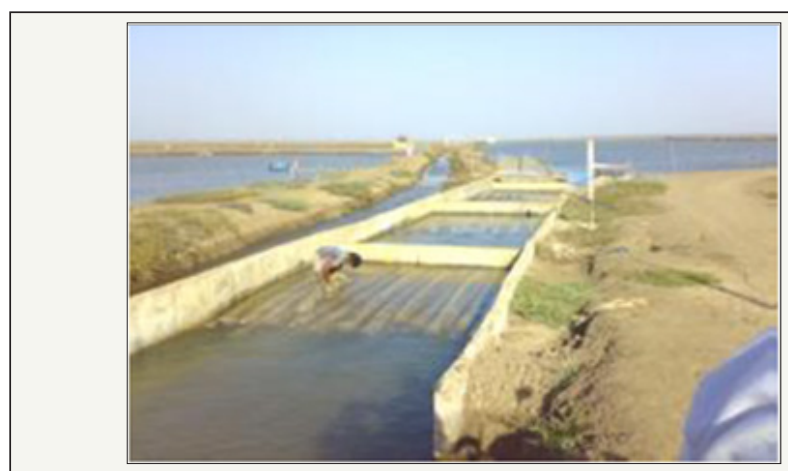

Figure 9: A filter unit consisting multiple filtration system in Surat area.

E. Ideal water cultivation practices are used, to develop natural healthy food along with natural helpful bacterial fauna to shrimps by applying both inorganic as well as organic fertilizers along with good quality pre-biotics and probiotics from reputed company.

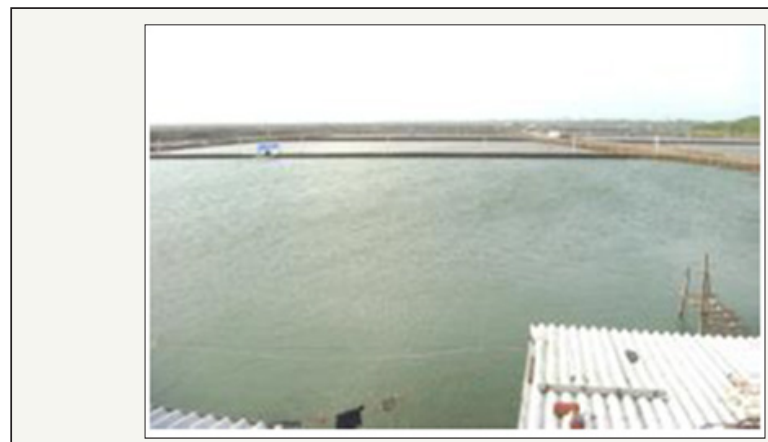

Figure 10: A well prepared pond ready to stock. 
F. Corrections of important water quality macro-parameters like salinity, $\mathrm{pH}$, alkalinity etc. used to make prior to stock of post larvae (Figure 10).

\section{Shrimp seed selection and stocking practices}

The success of shrimp farming purely depends upon selection of good quality seed, disease free post larvae is crucial to grow out practices. In contiguity to this following are the procedures that practiced in Surat area.

A. Post larvae used to select from those reputed hatcheries, having strong technical background, using good source of brood stocks from deep sea and not using any antibiotics. SAFA has identified those hatcheries in all over India as per their experience. SAFA technical personnel used to go those hatcheries and test the post larvae during three stages like PL 5-6, 10-12 and prior to pack, at least from two different PCR laboratories before making confirmation.

B. Finally good quality post larvae of size PL 15-20 from those listed hatcheries used to select with proper visual, microscopical and stress test along with viral analysis by PCR method from two different laboratories. This practice highly prevented the vertical transmission of virus to the culture system in Surat area, this resulted above $90 \%$ successful crop in last one decade.

C. Considering travelling time, number of post larvae used to pack in each bag, is strictly followed by farmers to minimize the stress to seed.

D. Post larvae used to acclimatize properly and carefully in farm with tank system prior to stocking inside the ponds for optimum survival rate.

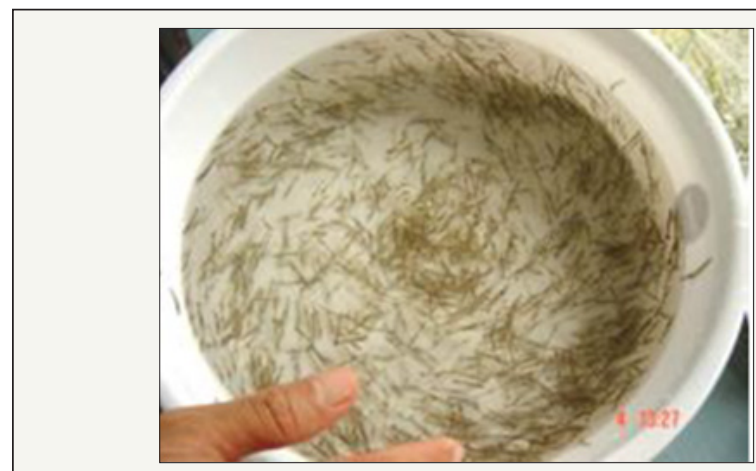

Figure 11: Good quality post larvae.

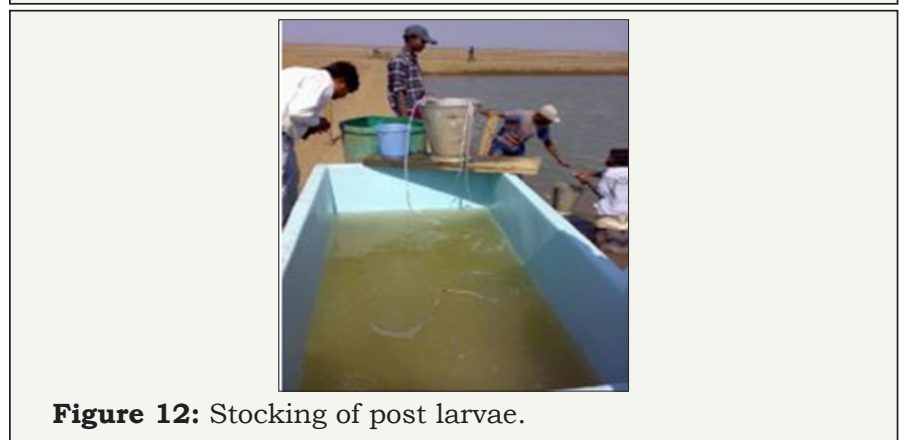

E. Weak and died shrimps if any used to separate and discard before stocking into the respective ponds (Figure 11,12).

\section{Water quality management practices}

Water quality management mainly lies on the maintenance of healthy algae bloom along with optimum physicochemical parameters in the pond. However, the following management practices used to follow in Surat area to maintain proper water quality for healthy environment to the cultured shrimp.

A. Maintain good water depth in culture ponds to give sufficient environmental space to culture shrimp. This is another one factor behind the successful culture story in Surat as discussed earlier.

B. Minimize use of water and water exchange were strictly followed. During critical stages like at the DOC of 80,100 and 120 little quantity of bottom water exchange practiced to minimize the ammonia, along with other toxic gases from the bottom. Usage of less water has reduces the chance of contamination and horizontal transmission of virus in the area.

C. Good quality of water as well as soil pro-biotics from reputed companies decided by SAFA technical personnel along with indigenous pre-biotics used to apply in regular interval with optimum doses to maintain proper water quality as well as for detritus management services (DMS) as the figure given below.

D. Sufficient required aeration facilities used to install in each culture pond in Surat area as shown in following figure and follow the proper mode operation as per quantity of carrying capacity of biomass.

E. Pond bottom used to check periodically i.e. at least once in a week and successive management used to follow as per requirement.

F. Proper bottom chaining used to practice twice weekly to clean feeding area and also to release toxic gases for effective pond bottom management as given in following (Figure 13,14).

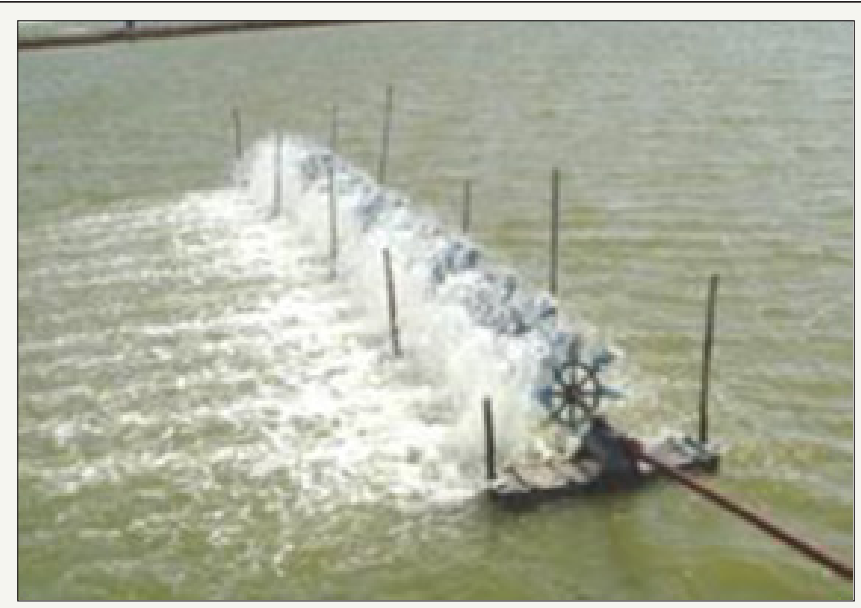

Figure 13: Good aeration in black tiger culture pond in Surat area. 


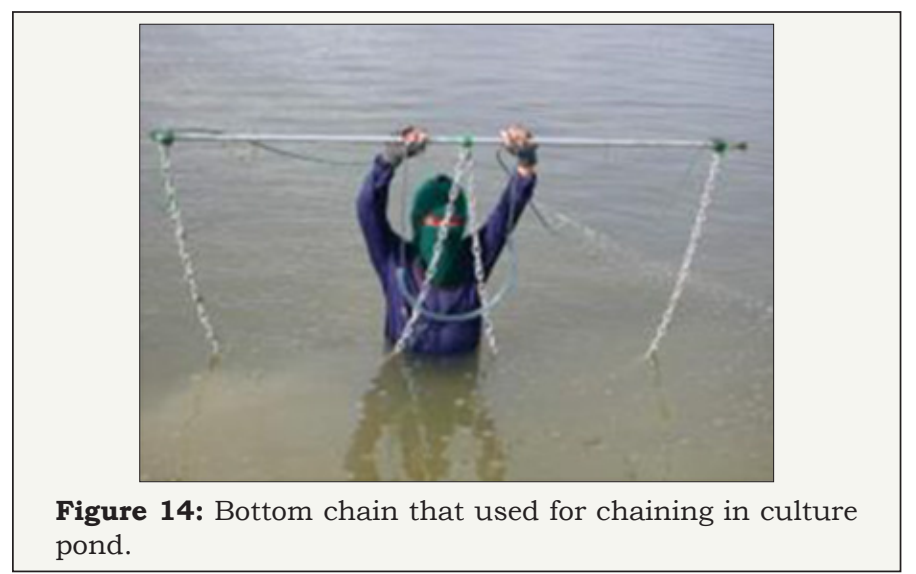

\section{Feed and feeding management practices}

A. Good quality nutritional balanced stable feed is very important component for profitable shrimp farming. Proper mode of feeding practice in farms with optimum food conversion ratio (F.C.R.) plays major role in growth, production and management of pond ecosystem, which are strictly follow in all shrimp farms under SAFA. Despite, some more tips that follow in Surat are briefed below.

B. SAFA's main target to minimize the feed conversion ration (F.C.R.) with good quality feed to reduce the cost of production.

C. Feed used to procure from top branded companies that have good international repute and consistency to its quality, which is jointly decided by SAFA senior technical personnel.

D. Judicious feeding method used to follow with correct size of feed as per growth stage of shrimp.

E. Proper check tray management used to practice for optimum feeding management along with observation of health of shrimps.

F. Proper moulting cycle used to check to avoid wastage of feed.

G. Feeding lines used to change once or twice in a crop.

H. While using any feed additives good binders with maximum stability were used.

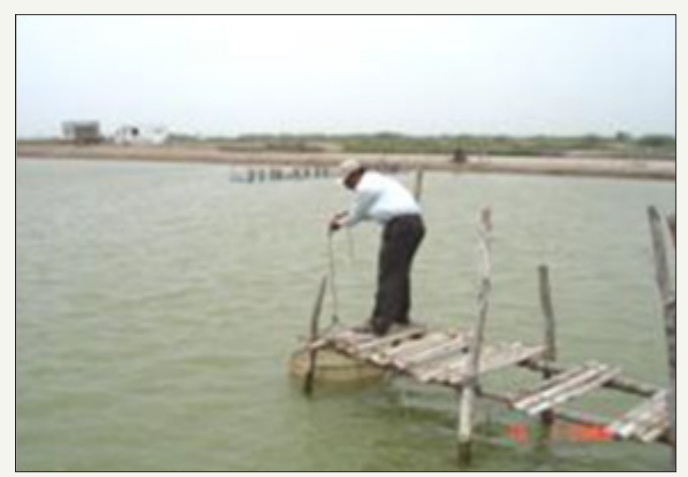

Figure 15: Checking of check tray by SAFA technical supervisor.
I. Good quality of gut probiotics with required dose from reputed companies were applied with feed in regular interval to reduce the risk of diseases and also to increase immunemodulation in shrimp (Figure 15,16).

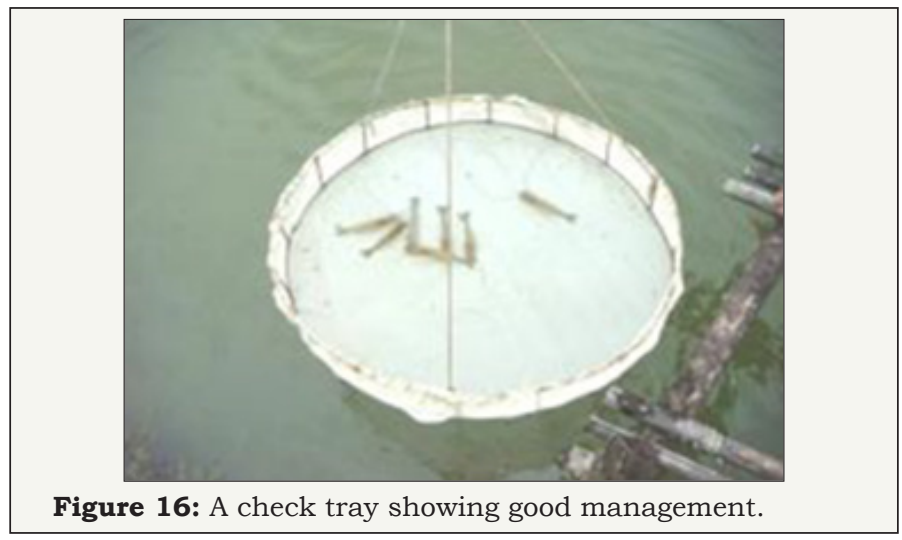

\section{Health Management and Biosecurity}

A. Growing shrimp health index were properly monitored by regular check tray observation and weekly sampling by cast net. Strictly biosecurity measures such as bird netting, crab fencing, footbath, hand wash etc. in all farms under SAFA were religiously followed to prevent viral out break. This strict biosecurity practices are the major steps, makes more successful crop for all Surat shrimp farmers. Some photographs showing biosecurity practices are given in the following (Figure 17-20).

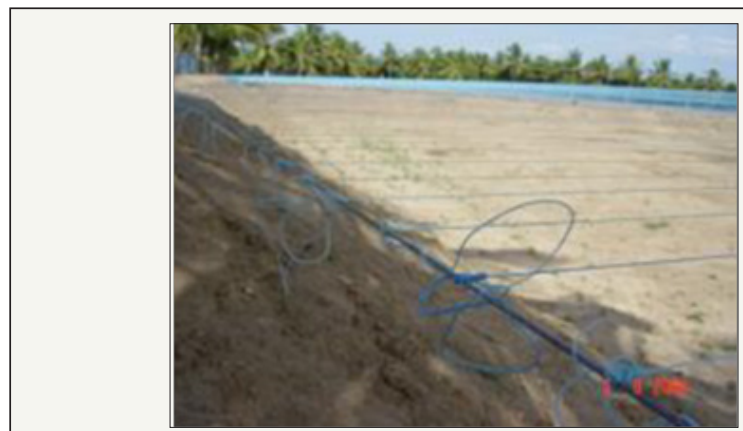

Figure 17: Bird netting to prevent birds inside culture ponds.

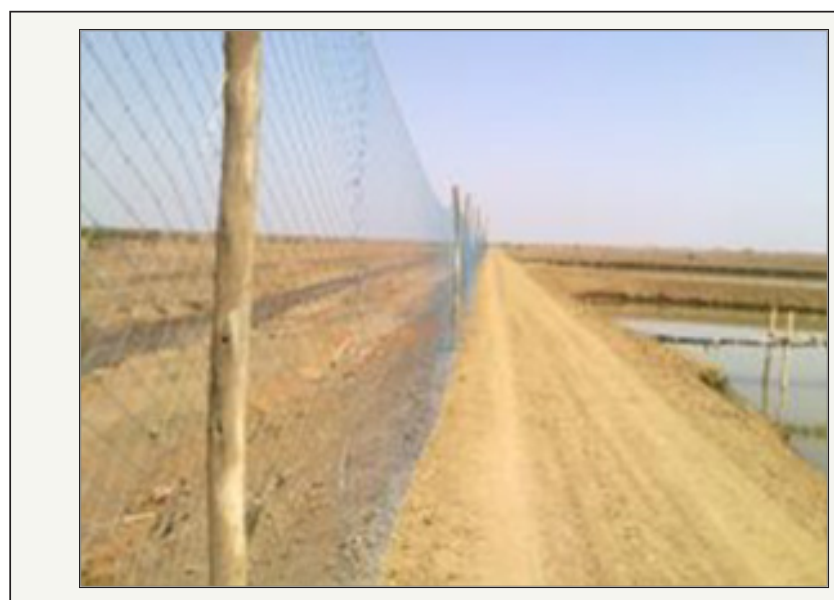

Figure 18: Crab fencing to prevent crab. 


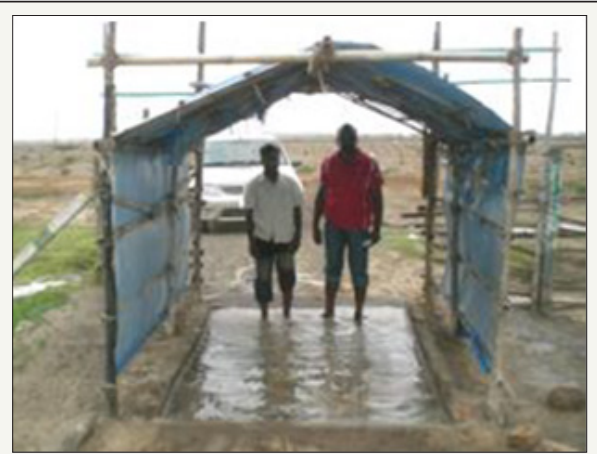

Figure 19: Foot wash before entering to the farm.

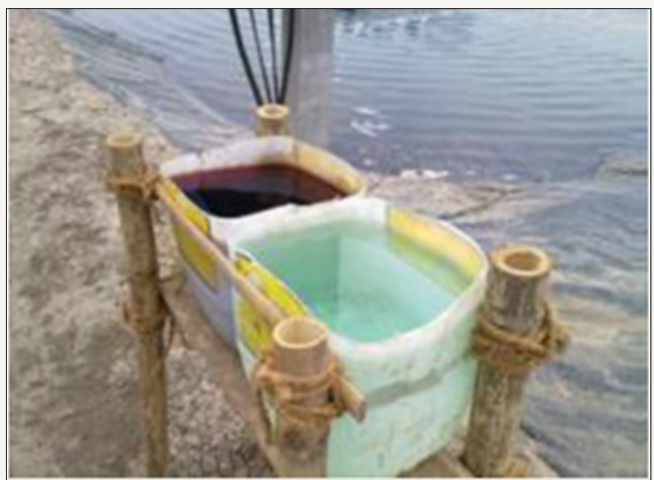

Figure 20: Hand wash before entering to the farm.

Harvest and Post-Harvest Handling Practices

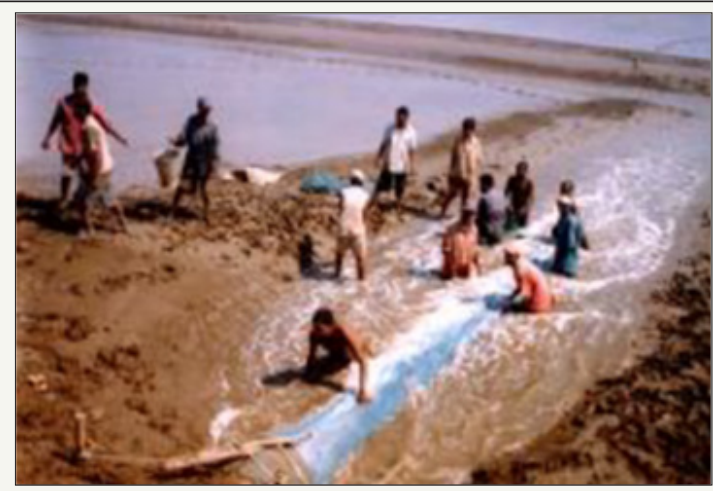

Figure 21: Complete harvest from drainage canal.

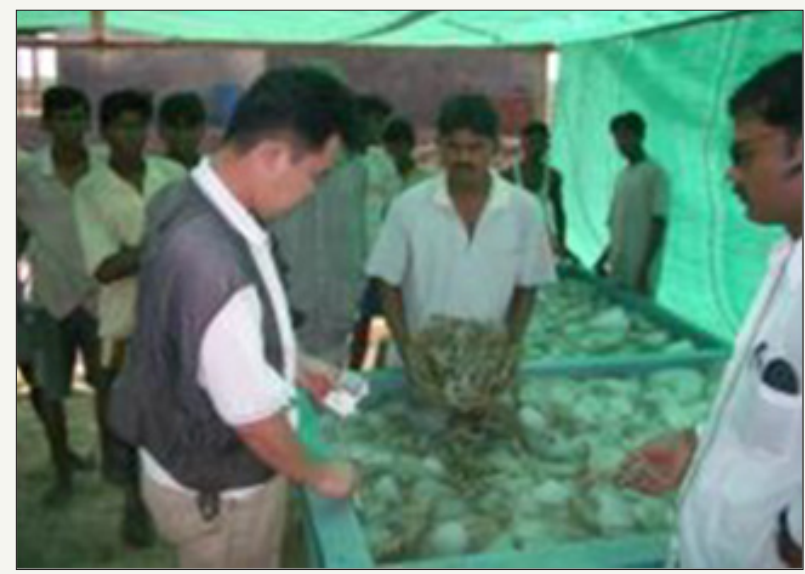

Figure 22: Post harvest practices in farm.

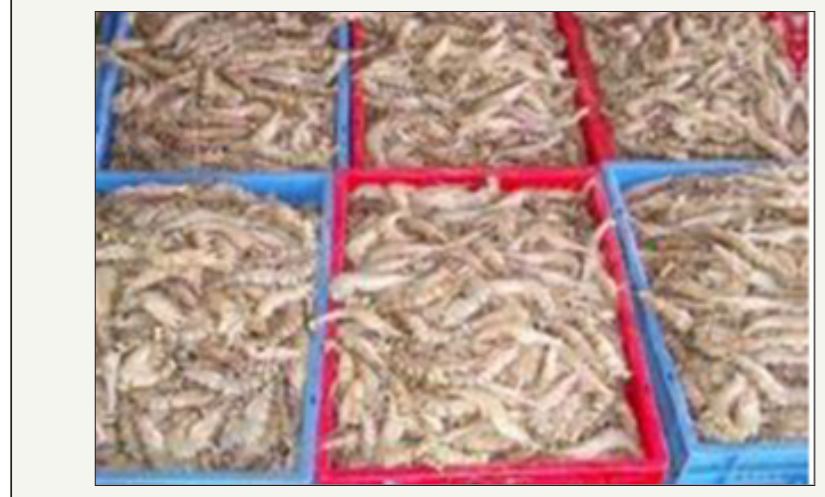

Figure 23: Good quality harvested shrimp.

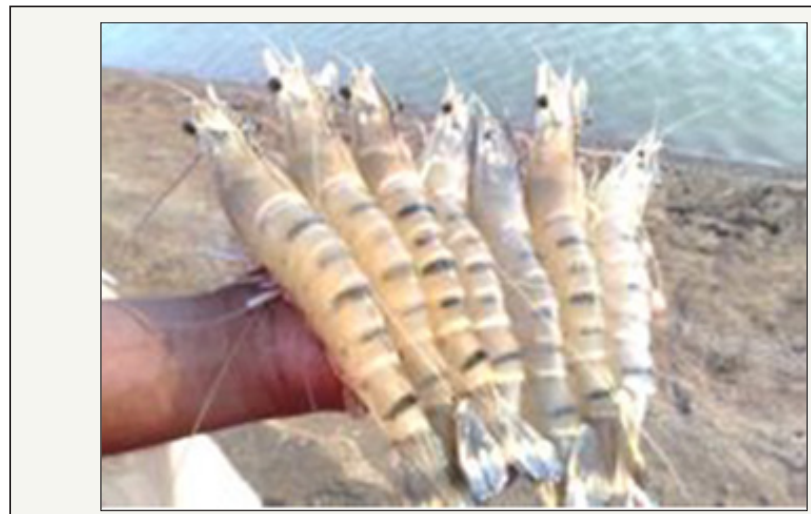

Figure 24: Good quality harvested shrimp.

Harvesting is the last and most important aspect of shrimp farming deciding the profitability of shrimp farms. It is vital to study proper market trend and rate before harvesting season. SAFA member farmers used to decide jointly to get the best price for their product from buyers. Harvesting used to do very carefully with minimum handing to maintain good quality of shrimp with hygienic conditions. Sufficient ration of shrimp to ice is used while packing and transporting to processing plant (Figure 21-24).

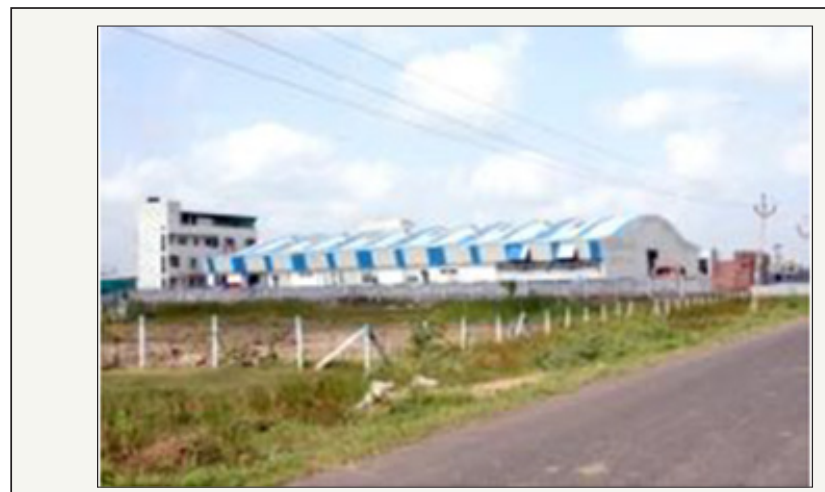

Figure 25: West Coast Frozen Food in Surat.

A. With the collective efforts of SAFA member farmers a well established processing plant of international standard is established in the heart of shrimp farming area in Surat. This has reduced the transportation and freezing time considerably. Short distance and less handling has minimized the post mortem changes of shrimp before bringing to processing plant. 
This maintains good quality of final product and commanded better price for farmers. Following figure is showing West Coast Frozen Food Private Limited, processing plant near the farming area in Surat (Figure 25,26).

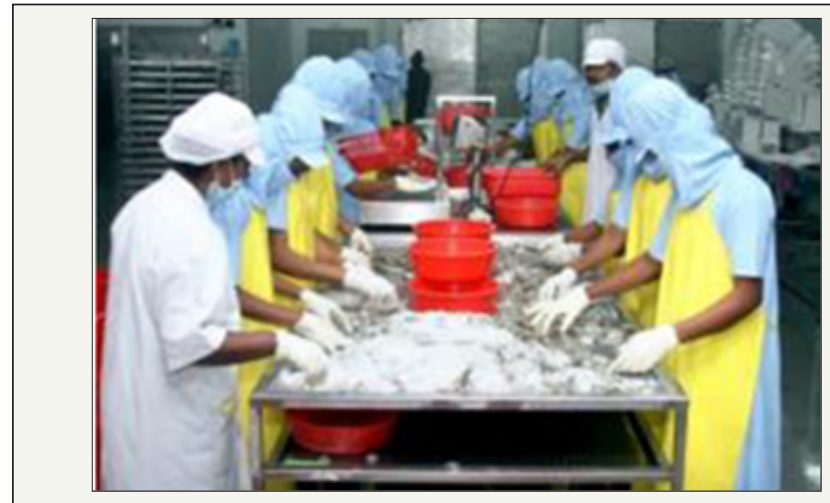

Figure 26: Post harvest practices in plant.

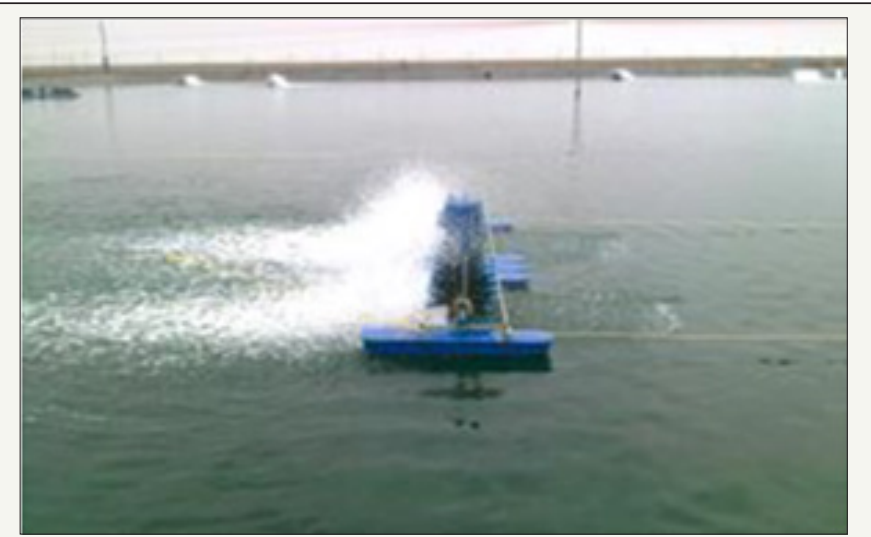

Figure 27: An experimental culture pond of white leg shrimp in Surat area.
B. SAFA has also welcomed the introduction of exotic white leg shrimp, Litopenaeus vannamei in Surat area as on experimental basis. Following figure shows an experimental white leg culture shrimp pond in Surat (Figure 27).

Following figure shows two most successful shrimp farmer in Surat area.

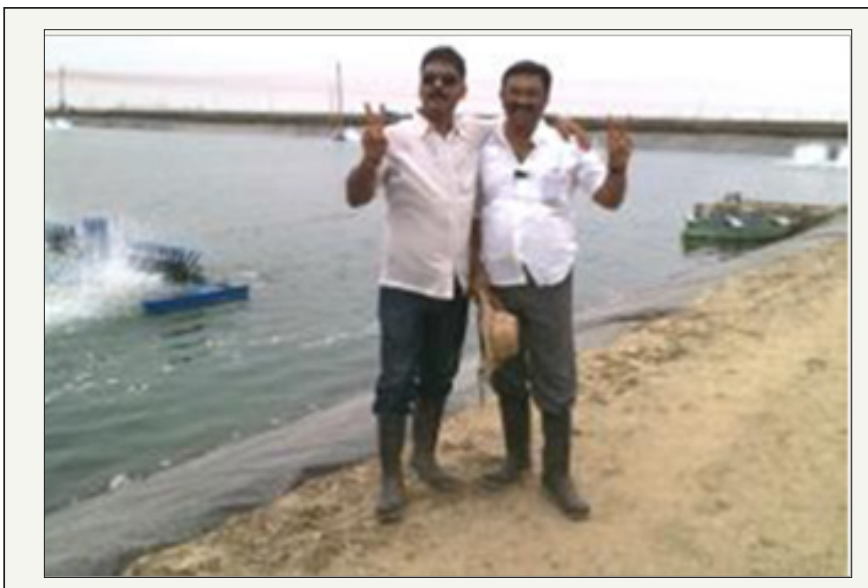

Figure 28: Most successful shrimp farmers in Surat (left Dr. Manoj M. Sharma-also main technical consultant for development of shrimp farms in Surat area)

(Figure 28): Most successful shrimp farmers in Surat (left Dr. Manoj M. Sharma- also main technical consultant for development of shrimp farms in Surat area).

C. These above practices that followed by SAFA in Surat area are the keys behind the most successful story of shrimp farming with $95 \%$ successful rate. In future SAFA is planning to develop more than 50,000hacters of area for brackish water aquaculture in Surat for "food and profit".

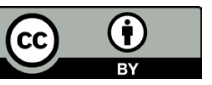

Creative Commons Attribution 4.0 International License

For possible submissions Click Here

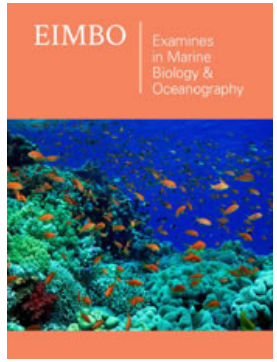

Examines in Marine Biology \& Oceanography

\section{Benefits of Publishing with us}

- High-level peer review and editorial services

- Freely accessible online immediately upon publication

- Authors retain the copyright to their work

- Licensing it under a Creative Commons license

- Visibility through different online platforms 